\title{
Hepatoprotective action of papain-hydrolyzed buffalo milk protein on carbon tetrachloride oxidative stressed albino rats
}

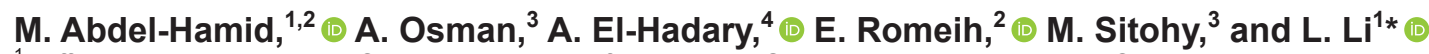 \\ ${ }^{1}$ Buffalo Research Institute, Chinese Academy of Agricultural Sciences, Nanning 530001, China \\ ${ }^{2}$ Dairy Science Department, Faculty of Agriculture, Cairo University, Giza 12613, Egypt \\ ${ }^{3}$ Biochemistry Department, Faculty of Agriculture, Zagazig University, Zagazig 44511, Egypt \\ ${ }^{4}$ Biochemistry Department, Faculty of Agriculture, Banha University, Banha 13736, Egypt
}

\begin{abstract}
Buffalo skim milk retentate was hydrolyzed with papain for $4 \mathrm{~h}$ (enzyme:substrate, 1:200), resulting in a retentate hydrolysate $(\mathrm{RH})$ with a degree of hydrolysis of $23 \%$. We then investigated the potential hepatoprotective activity of $\mathrm{RH}$ at 250 and $500 \mathrm{mg} / \mathrm{kg}$ of body weight per day on carbon tetrachloride $\left(\mathrm{CCl}_{4}\right)$-induced oxidative stress in albino rats. Liver biomarkers (alanine aminotransferase, aspartate aminotransferase, alkaline phosphatase, and lactate dehydrogenase), kidney biomarkers (urea, creatinine), and serum lipid profile (total lipids and triglycerides) were measured, in addition to histopathological status. Injection of $\mathrm{CCl}_{4}$ significantly increased all liver and kidney biomarkers compared with the negative control. In contrast, $\mathrm{CCl}_{4}$ injection significantly reduced hepatic antioxidant enzyme activities; that is, glutathione peroxidase and superoxide dismutase. Oral administration of RH for $28 \mathrm{~d}$ effectively maintained a physiologically normal range of liver and kidney biomarkers compared with the positive control. Furthermore, RH administration significantly increased activities of glutathione peroxidase and superoxide dismutase. Histopathological sections of $\mathrm{CCl}_{4^{-}}$ stressed rats treated with $\mathrm{RH}$ were different from that of the positive control and were similar to those of the negative control, in a concentration-dependent manner. Our results demonstrated the antihepatotoxic activities of buffalo milk $\mathrm{RH}$ and demonstrated that the higher $\mathrm{RH}$ concentration (500 $\mathrm{mg} / \mathrm{kg}$ of body weight per day) could maintain the healthy biological status of the $\mathrm{CCl}_{4}$-injected rats.
\end{abstract}

Key words: buffalo milk retentate, papain hydrolysate, hepatoprotective effect, carbon tetrachloride

Received July 30, 2019.

Accepted October 11, 2019.

*Corresponding author: lling2010@163.com

\section{INTRODUCTION}

The liver is the main organ controlling several physicochemical functions of the body. However, hepatic parenchyma injury may have deleterious effects on these physicochemical functions (Wolf, 1999). Hepatic injury is usually incurred by toxic chemicals such as carbon tetrachloride or by infection (Yang et al., 2013). Although drugs have been developed to treat chronic liver disturbances, they often have side effects (Mahmoud et al., 2012). Additionally, efficient modern drugs for the treatment of chronic and acute liver damage are very scarce (Vuda et al., 2012). Therefore, there is emerging interest in exploring natural materials to find more effective and safer alternatives to synthetic drugs. In this context, studies have been conducted on the hepatoprotective activity of numerous natural sources such as cold-pressed Syzygium aromaticum oil (El-Hadary and Ramadan Hassanien, 2016), medicinal plants (Taha and Osman, 2015), and natural pigments and proteins (Ou et al., 2010; Yu et al., 2012) using several experimental models. Free radicals; that is, the hydroxyl radical $\left({ }^{\bullet} \mathrm{OH}\right)$ and superoxide anion radical $\left(\mathrm{O}_{2}{ }^{\bullet-}\right)$, are very reactive oxygen species with single and unpaired electrons that can intervene in the biological oxidation pathway, causing numerous adverse effects on biological systems and food quality. Free radicals, produced via oxidative metabolism in human organs, can induce several diseases, including cancer, arteriosclerosis, and liver damage, which can be caused artificially by exposure to an excess of substances such as alcohol, bromobenzene, and $\mathrm{CCl}_{4}$ (Cai et al., 2017).

Buffalo is the second-highest producer of milk worldwide and the species is widely distributed in Asia and Africa. Buffalo milk has high protein content (3.8-4.5\%) compared with cow, sheep, and goat milks, and it is a valuable source of protein for nutritional and health applications (Mahmood and Usman, 2010). Generally, bioactive peptides released from different protein sources via enzymatic hydrolysis are good sources for antioxidants and antibacterial activities 
(Otte et al., 2015; Abdel-Hamid et al., 2016; Osman et al., 2016a,b). Recently, buffalo milk retentate has been used as a substrate for different proteases, especially papain, releasing in vitro bioactive peptides with high antioxidant and high angiotensin-converting enzyme (ACE)-inhibitory activities (Abdel-Hamid et al., 2017). We planned the current study based on results obtained in Abdel-Hamid et al. (2017) to further assess in vivo the potential hepatoprotective action of the buffalo skim milk retentate hydrolysate $(\mathbf{R H})$, prepared using papain, against $\mathrm{CCl}_{4}$-induced liver injury in male albino rats.

\section{MATERIALS AND METHODS}

\section{Materials}

Buffalo skim milk retentate ( $17.5 \%$ total protein) was prepared using UF technology as described in Abdel-Hamid et al. (2017). Commercial kits used in this study for measuring biochemical parameters (i.e., liver and kidney bioindicators and serum lipid profile) were obtained from Biodiagnostic Co. (Giza, Egypt). Papain (from Carica papaya L.) was purchased from Sigma Aldrich (St. Louis, MO). Carbon tetrachloride was purchased from El-Gomhoreya Co. (Cairo, Egypt). All other chemicals used in this work were of analytical grade and purchased from El-Gomhoreya Co. (Zagazig, Egypt).

\section{Buffalo Skim Milk Retentate Hydrolysis}

Buffalo skim milk retentate was hydrolyzed according to our pervious study (Abdel-Hamid et al., 2017). In brief, buffalo skim milk retentate was hydrolyzed with papain (enzyme:substrate ratio of 1:200, wt/wt) at $\mathrm{pH}$ 6 for $4 \mathrm{~h}$ at $37^{\circ} \mathrm{C}$. To inactivate the papain enzyme, the hydrolysate was heated for $10 \mathrm{~min}$ in a boiling water bath then centrifuged at $4,000 \times g$ for $30 \mathrm{~min}$. The resultant RH showed a $23 \%$ degree of hydrolysis as determined by trinitrobenzenesulfonic acid (TNBS) method according to Adler-Nissen (1979). Additionally, the obtained $\mathrm{RH}$ had a concentration required to scavenging $50 \%$ of 2,2 '-azino-bis(3-ethylbenzothiazoline-6-sulfonic acid (ABTS) radicals of $30.5 \mu \mathrm{g} / \mathrm{mL}$, which was measured as reported by Abdel-Hamid et al. (2017).

\section{Animals and Experimental Design}

The design and procedures of the biological experiment were approved by the Institutional Animal Care and Use Committee of Zagazig University (ZU-IA-
CUC). Twenty adult healthy male albino rats (Wister strain, weighting 130-150 g $\pm 10 \mathrm{~g}$ of BW) supplied by the Organization of Biological Products \& Vaccine (Helwan farm, Cairo, Egypt) were used in the present study. Animals were housed in plastic cages under ambient temperature $\left(25 \pm 1^{\circ} \mathrm{C}\right)$ with successive 12-h cycles of light and dark (El-Saadany et al., 1991; Sitohy et al., 2013). The animals were provided with water ad libitum and administered a basal diet according to the AIN-93 guidelines (Reeves, 1997) throughout 28 d. The animals were randomly divided into 4 groups (G1 to G4), consisting of 5 rats each: G1 served as the negative control (rats did not receive any treatment), whereas rats in G2 to G4 were treated with a single dose of $50 \% \mathrm{CCl}_{4}$ in corn oil $(0.5 \mathrm{~mL} / \mathrm{kg}$ of $\mathrm{BW}$ ) via intraperitoneal injection. Rats in G2 served as positive controls (injury group; did not receive any further treatment), whereas rats in G3 and G4 were administered $\mathrm{RH}$ orally at concentrations of 250 and $500 \mathrm{mg} / \mathrm{kg}$ of BW per day, respectively, for $28 \mathrm{~d}$ at the same time as $\mathrm{CCl}_{4}$ injection.

\section{Blood Sampling and Analysis}

At the end of the experiment, blood samples were drawn from the retro-orbital plexus veins of individual rats using fine capillary heparinized tubes and allowed to clot before separating the serum by centrifugation at $1,000 \times g$ at $4^{\circ} \mathrm{C}$ for $15 \mathrm{~min}$. Serum was used to determine liver and kidney bioindicators and serum lipid profile. Serum aspartate aminotransferase (AST), alanine aminotransferase (ALT), lactate dehydrogenase (LDH), alkaline phosphatase (ALP), urea and creatinine levels, as well as total protein and albumin were measured using spectrophotometric methods (Reitman and Frankel, 1957; Allain et al., 1974; Bradford, 1976; Tabacco et al., 1979; Laborde et al., 1995). Serum globulin was calculated by subtracting serum albumin from total serum protein (Osman et al., 2019). Total lipids and triglycerides analyses were performed according to Ramadan et al. (2008).

\section{Antioxidant Markers}

Liver samples were immediately rinsed with ice-cold saline to remove blood remnants. Liver tissue was homogenized in cold potassium phosphate saline $(0.1 \mathrm{M}$, $\mathrm{pH}=7.4)$ at a ratio of $1: 9(\mathrm{wt} / \mathrm{vol})$, and centrifuged at $5,000 \times g$ for $10 \mathrm{~min}$ at $4^{\circ} \mathrm{C}$. The supernatant was used to determine the antioxidant markers. Malondialdehyde (MDA), glutathione (GSH), superoxide dismutase (SOD), and catalase (CAT) were measured by a colo- 
rimetric method using kits according to the protocol provided by the manufacturer (Biodiagnostic Co.).

\section{Histopathological Status}

Fresh liver tissue specimens were rapidly fixed in $10 \%$ neutral buffered formalin, and paraffin sections were prepared and stained with hematoxylin and eosin stain for histopathological examination. The liver sections were examined for the degree of the histopathological hepatic injury. Signs of degeneration-hepatocyte necrosis, fatty change, hyaline degeneration, and ballooning degeneration - were observed and recorded.

\section{Statistical Analysis}

The statistical package program SPSS 22 for Windows (IBM Corp., Armonk, NY) and one-way ANOVA were used to analyze the data. Subsequently, a post hoc test implying the least significant difference (LSD) was applied to make multiple comparisons between all studied treatments. The results are expressed as the mean \pm standard deviation (SD). Pearson correlation coefficients were determined between all parameters to measure the strength of their relationship.

\section{RESULTS}

\section{Serum Enzymes}

The effect of $\mathrm{RH}$ administration on serum enzymes ALT, AST, ALP, and LDH in albino rats stressed by $\mathrm{CCl}_{4}$ is shown in Figure 1. Administration of $\mathrm{CCl}_{4}$ resulted in significantly $(P<0.05)$ higher levels of ALT, AST, ALP, and LDH in the positive control group (G2) compared with the negative control group (G1). Oral administration of $\mathrm{RH}$ at 2 levels $(250$ and $500 \mathrm{mg} /$ $\mathrm{kg}$ of BW per day) significantly $(P<0.05)$ prevented increases in the 4 biomarkers compared with the positive control (G2) in a concentration-dependent manner. The G4 treatment (500 mg $/ \mathrm{kg}$ of BW per day) did not differ $(P>0.05)$ in AST, ALP, and LDH concentrations
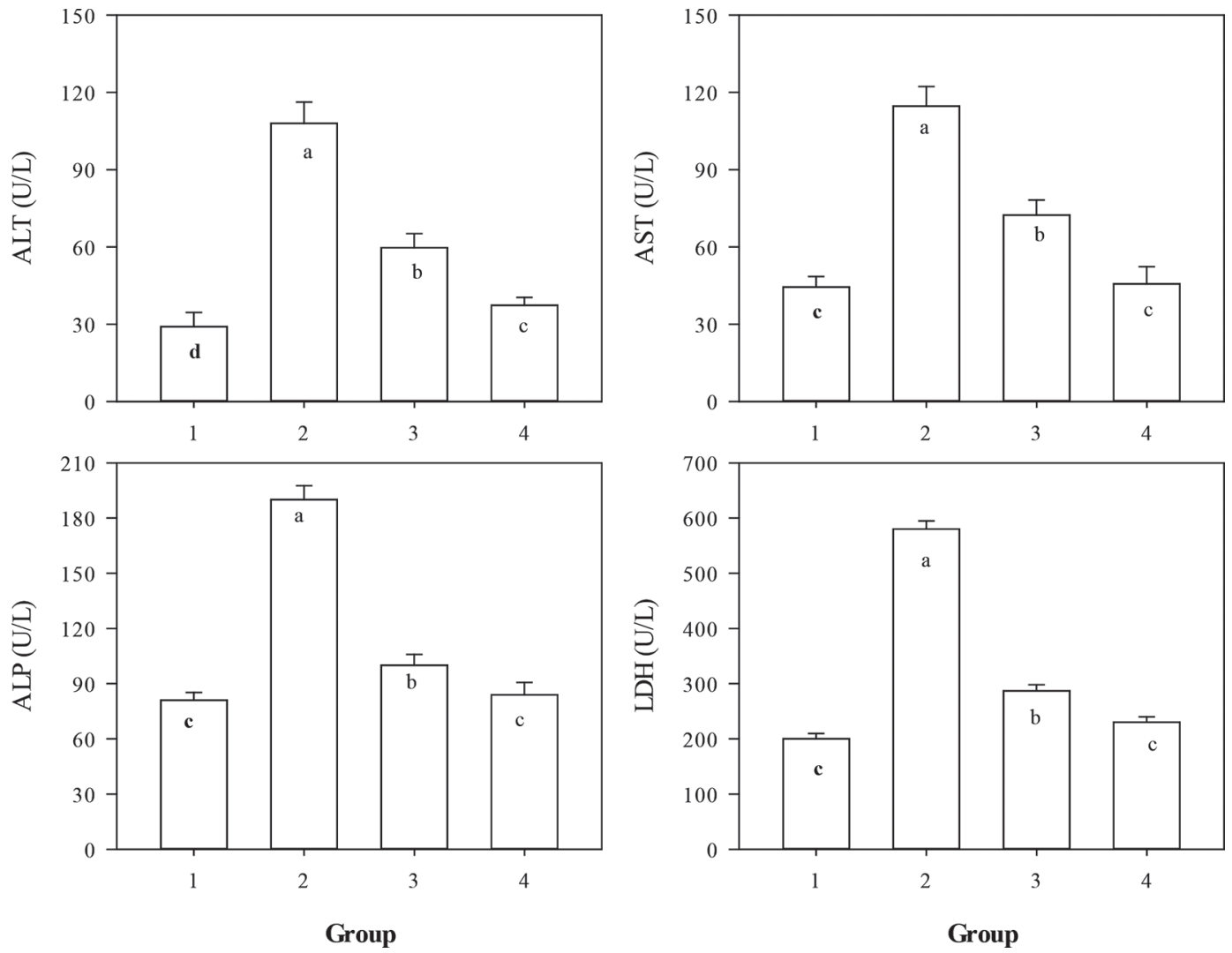

Figure 1. Serum alanine aminotransferase (ALT), aspartate aminotransferase (AST), alkaline phosphatase (ALP), and lactate dehydrogenase $(\mathrm{LDH})$ of albino rats receiving the same level of $\mathrm{CCl}_{4}$ as the positive control but treated with 2 levels of buffalo milk retentate hydrolysate (RH): 250 and $500 \mathrm{mg} / \mathrm{kg}$ of BW per day [group (G) 3 and G4, respectively] compared with the negative and positive controls (G1 and G2, respectively). Different letters indicate significant differences $(P<0.05)$. Error bars represent standard deviations. 

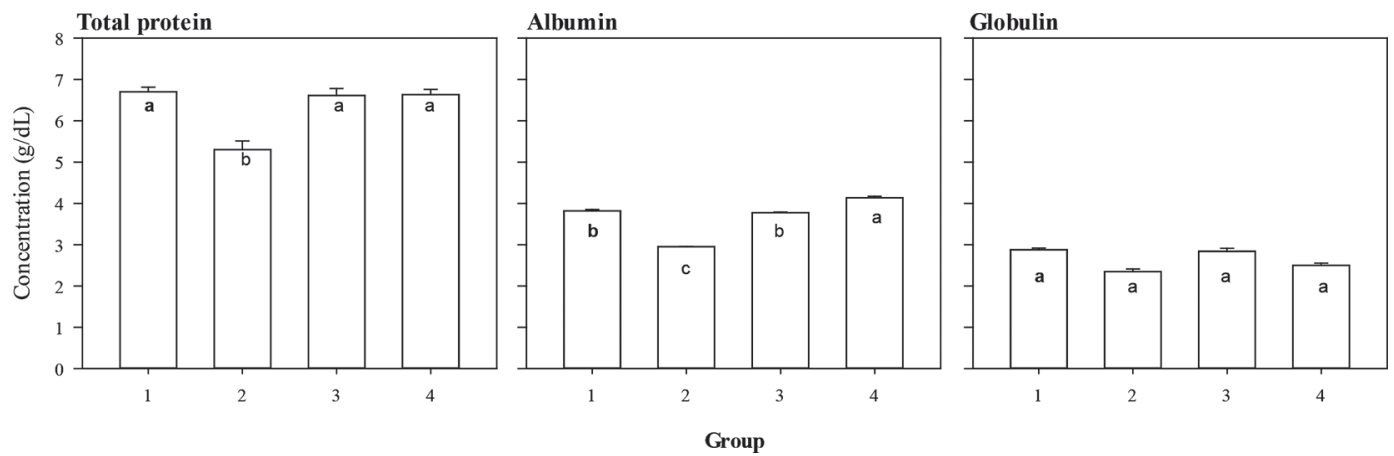

Figure 2. Serum protein levels (total protein, albumin and globulin) in albino rats receiving the same level of $\mathrm{CCl}_{4}$ as the positive control but treated with 2 levels of buffalo milk retentate hydrolysate $(\mathrm{RH}): 250$ and $500 \mathrm{mg} / \mathrm{kg}$ of BW per day [group (G) 3 and G4, respectively] compared with the negative and positive controls (G1 and G2, respectively). Different letters indicate significant differences $(P<0.05)$. Error bars represent standard deviations.

compared with the negative control (G1). However, it showed significantly lower ALT, AST, ALP, and LDH concentrations $(45,37,47$, and $51 \%$, respectively) than the positive control (G2).

\section{Protein and Lipid Profiles}

Total protein, albumin, and globulin levels in blood serum of the 4 experimental rat groups are shown in Figure 2. The levels of total protein and albumin in the positive control $(\mathrm{G} 2)$ were significantly $(P<0.05)$ decreased, by 21 and $23 \%$, respectively, compared with the negative control. These negative effects of $\mathrm{CCl}_{4}$ were ameliorated by $\mathrm{RH}$ administration in treatments G3 and G4. The levels of total proteins and albumin were significantly $(P<0.05)$ higher in G3 and G4 than in $\mathrm{G} 2$, and did not differ significantly $(P>0.05)$ from the negative control group (G1). Oral administration of $\mathrm{RH}$ had no effect on globulin level.

Concerning the lipid profile, Figure 3 shows that levels of total lipids and triglycerides in the positive control group (G2) were significantly $(P<0.05)$ higher than those of the negative control group (G1). The levels of total lipids and triglycerides in G3 and G4 were significantly $(P<0.05)$ lower than those in positive control (G2) and close to the levels of the negative control $(P>0.05)$ as a result of $\mathrm{RH}$ administration at 2 dosages (250 and $500 \mathrm{mg} / \mathrm{kg}$ of BW per day).

\section{Renal Biomarkers}

Data in Figure 4 show changes in the levels of urea and creatinine in the 4 albino rat groups. The serum levels of urea and creatinine in G2 were significantly $(P<0.05)$ higher than those of the negative control (G1), being higher by 176 and $163 \%$, respectively. The
RH treatments (G3 and G4) showed significantly $(P<$ 0.05 ) lower levels of kidney biomarkers (44 and $40 \%$ for G3, and 54 and $59 \%$ for G4, respectively), compared with the positive control (G2). The higher dosage of $\mathrm{RH}(500 \mathrm{mg} / \mathrm{kg}$ of BW per day) was able to maintain a serum creatinine level within the normal range.

\section{Hepatic Oxidative Stress Biomarkers}

Changes in levels of some oxidative stress parameters in the liver of albino rats are shown in Figure 5. The levels of SOD and CAT in the positive control (G2) were significantly $(P<0.05)$ lower $(53$ and $59 \%$, respectively) than those of the negative control (G1). Treating the $\mathrm{CCl}_{4}$-stressed albino rats with $\mathrm{RH}$ at 2 dosages (G3 and G4) restored the levels of these vital antioxidant enzymes. Significantly lower levels of SOD and CAT were found in G3 (20 and 28\%) and G4 (7 and $11 \%$ ) compared with the negative control (G1).

Malondialdehyde is the main degradation product of lipid peroxidation in liver tissue. Figure 5 shows that the positive control group (G2) had the highest MDA value, $205 \%$ higher than that of the negative control (G1). Oral administration of RH (250 and $500 \mathrm{mg} / \mathrm{kg}$ of BW per day) significantly $(P<0.05)$ prevented an increase of MDA levels in a concentration-dependent manner compared with the positive control (G2). Furthermore, administration of the high dosage of RH (G4) did not change $(P>0.05)$ the MDA level compared with the negative control.

Rats in the positive control group exhibited the lowest GSH value among experimental groups (Figure 5). Administration of $\mathrm{RH}$ significantly $(P<0.05)$ increased GSH values compared with that of the positive control (G2). The higher RH dosage (G4) resulted in a greater increase in GSH level than the lower dosage (G3) and 
did not differ $(P>0.05)$ from that of the negative control group (G1).

\section{Histopathology}

The effect of $\mathrm{RH}$ administration on liver histopathology characteristics is shown in Figure 6. The histopathological profiles support the serum biochemical measurements. Fibrosis was detected in the portal area of liver sections from rats in the positive control group treated with $\mathrm{CCl}_{4}$, whereas normal histological structures of the central vein and surrounding hepatocytes in the hepatic parenchyma can be seen in the liver lobules
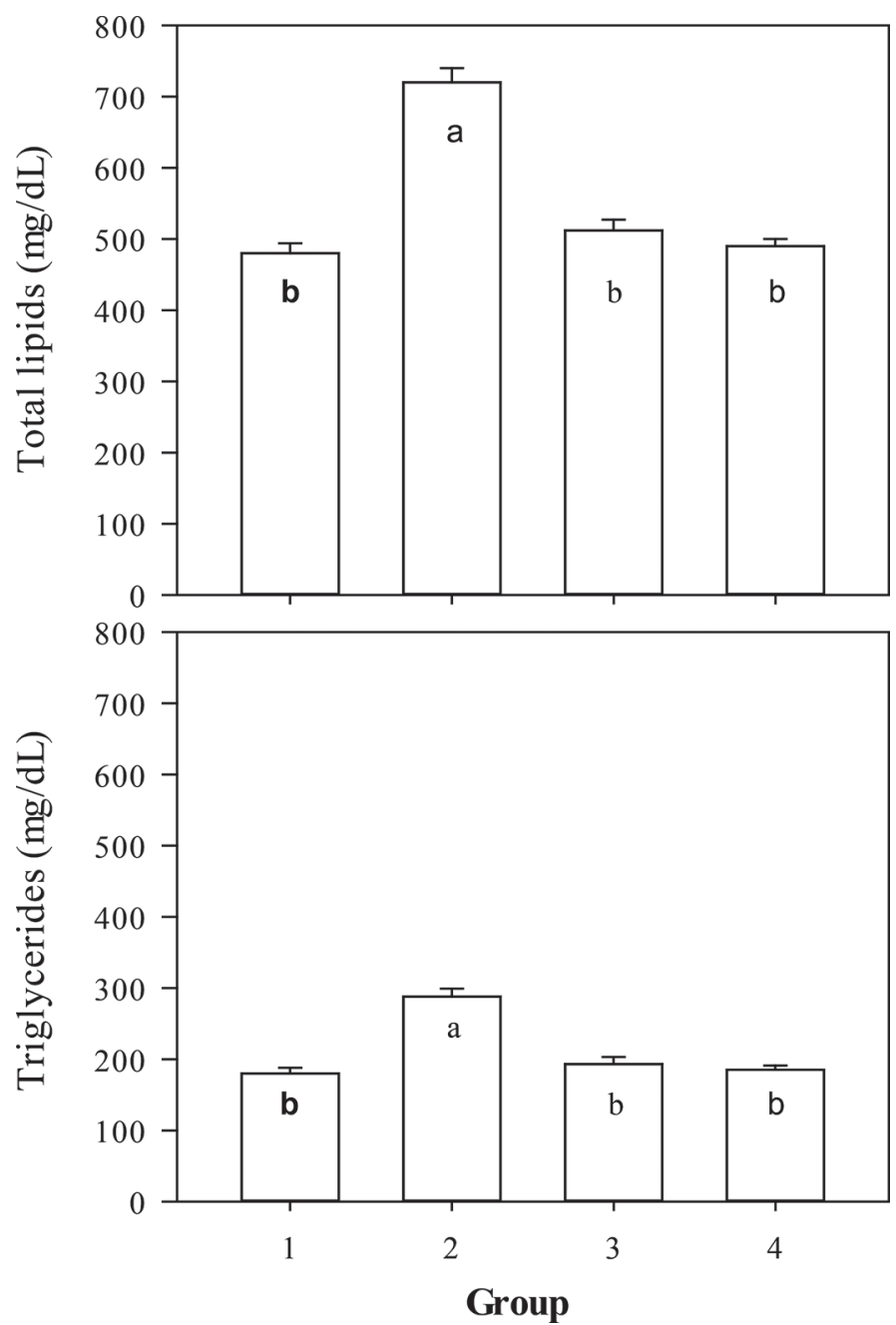

Figure 3. Serum total lipids and triglycerides of albino rats receiving the same level of $\mathrm{CCl}_{4}$ as the positive control but treated with 2 levels of buffalo milk retentate hydrolysate $(\mathrm{RH}): 250$ and $500 \mathrm{mg} /$ $\mathrm{kg}$ of BW per day [group (G) 3 and G4, respectively] compared with the negative and positive controls (G1 and G2, respectively). Different letters indicate significant differences $(P<0.05)$. Error bars represent standard deviations. of the negative control. The histopathological sections of liver from rats subjected to $\mathrm{CCl}_{4}$ stress and treated with RH did not show major structural alterations and were similar to those of the negative control.

\section{DISCUSSION}

The main objective of the current study was to verify the potential hepatoprotective action in vivo of buffalo milk RH obtained by papain based on our previous in vitro results (Abdel-Hamid et al., 2017). Retentate
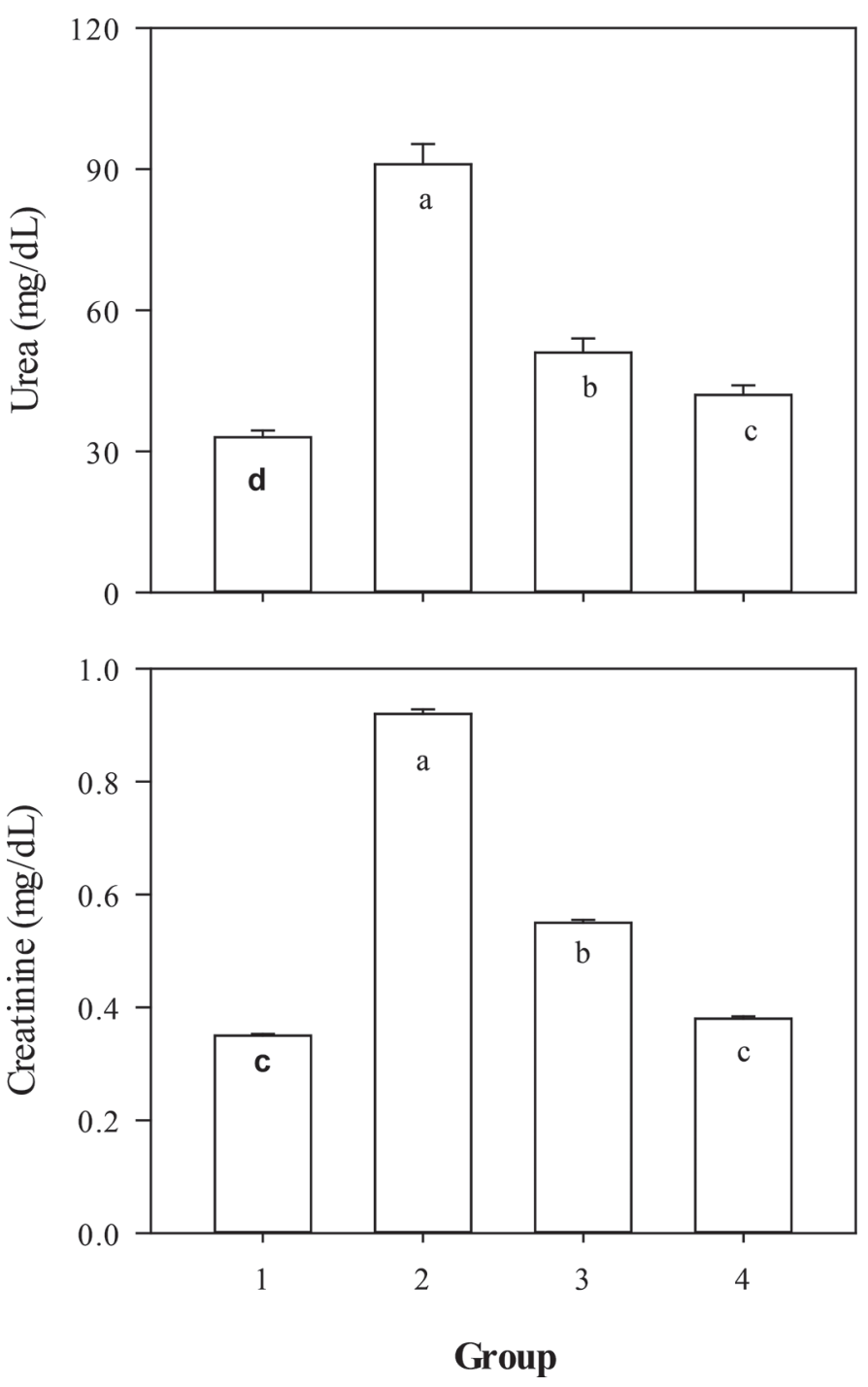

Figure 4. Serum urea and creatinine of albino rats receiving the same level of $\mathrm{CCl}_{4}$ as the positive control but treated with 2 levels of buffalo milk retentate hydrolysate (RH): 250 and $500 \mathrm{mg} / \mathrm{kg}$ of BW per day [group $(\mathrm{G}) 3$ and $\mathrm{G} 4$, respectively] compared with the negative and positive controls (G1 and G2, respectively). Different letters indicate significant differences $(P<0.05)$. Error bars represent standard deviations. 
hydrolysate contains both bioactive peptide sequences; for example, ACE-inhibitory peptides (FPGPIPK, IPPK, IVPN, and QPPQ) and antioxidant peptides (YPSG, HPFA, and KFQ; Abdel-Hamid et al., 2017). The superiority of casein hydrolysates to intact casein in inhibiting lipid oxidation was additionally attributed to its high scavenging of free radicals (Díaz et al., 2003). The abundance of bioactive peptides obtained in this $\mathrm{RH}$ may explain its potential hepatoprotective influence against oxidative stress artificially induced in albino rats by $\mathrm{CCl}_{4}$, an industrial hepatotoxic solvent exerting oxidative stress through free radical formation in different animal tissues (Jiang et al., 2012). Acute $\mathrm{CCl}_{4}$-induced hepatotoxicity occurs by activating reactive metabolites capable of triggering lipid peroxidation, cell membrane damage, and multiple pathological processes (Manibusan et al., 2007).

The transaminases (ALT, AST) are cytoplasmic in nature; however, if liver is injured, these enzymes can enter into the circulatory system because of modified membrane permeability (Shenoy et al., 2002). The observed increases in serum AST, ALT, ALP, and LDH biomarkers in $\mathrm{CCl}_{4}$-treated animals in the current study may indicate hepatic cell damage, according to Wolf (1999). In contrast, normal levels of these biomarkers in the RH-treated groups may reflect the hepatoprotective action of $\mathrm{RH}$ against acute $\mathrm{CCl}_{4}$-induced liver injury. These findings are consistent with those reported for bovine whey protein hydrolysate (Hamad et al., 2011) and other naturally active antioxidant agents (Vuda et al., 2012; Yu et al., 2012; Taha and Osman, 2015; ElHadary and Ramadan Hassanien, 2016). The results demonstrate that the high dosage of $\mathrm{RH}$ was able to alleviate increases in 3 biomarkers (AST, LDH, and ALP) induced by $\mathrm{CCl}_{4}$, with levels closer to those of the negative control group (G1). However, ALT was still higher in G3 and G4 than in the negative control (G1), referring to the impotency of this product to completely act as hepatoprotection at these concentrations. Although the low dosage of $\mathrm{RH}$ could not completely prevent liver damage, its action was still significant and considerable. These results confirm that the protective action of $\mathrm{RH}$ is correlated with its biochemical identity and activity.
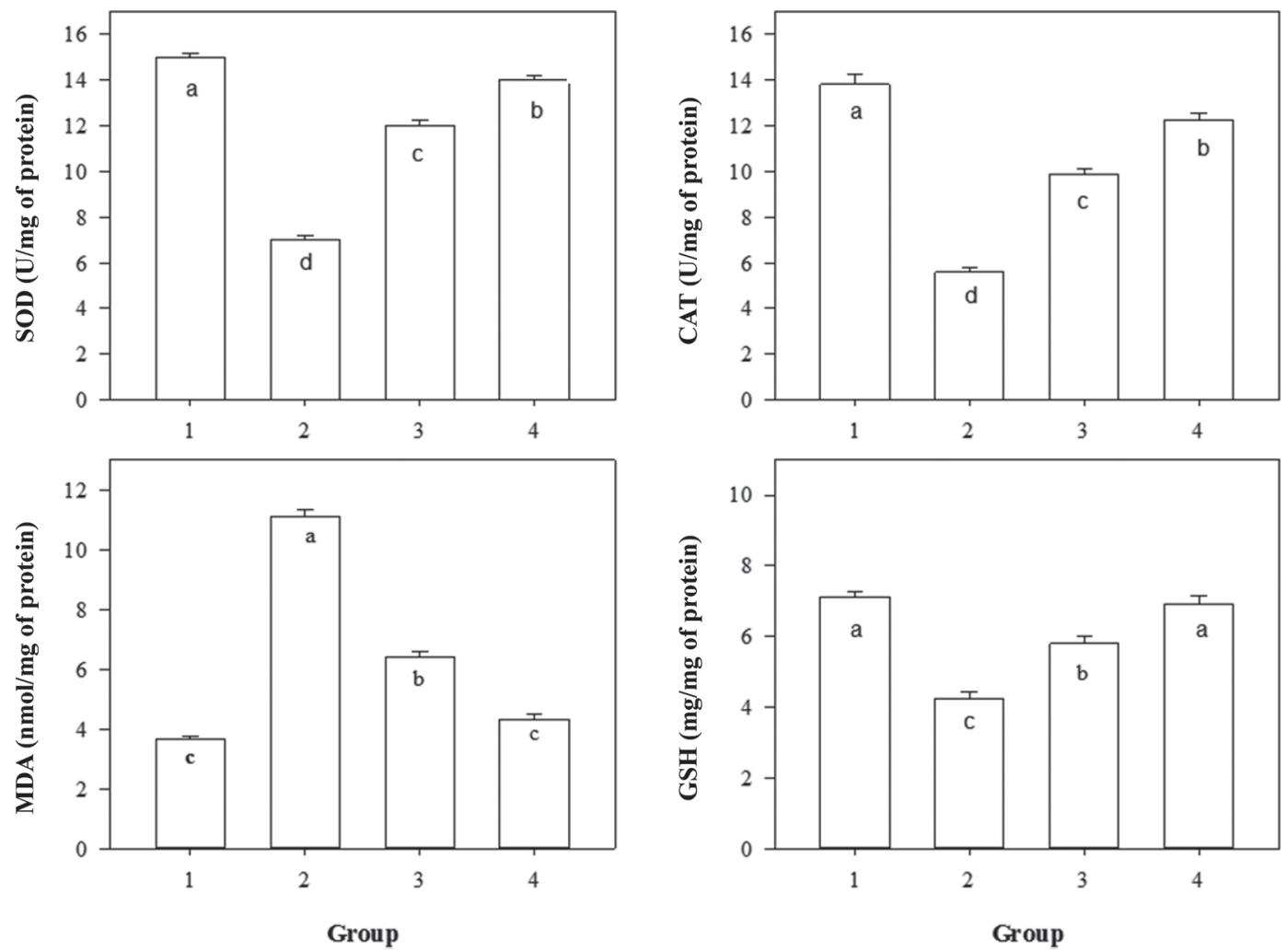

Figure 5. Serum superoxide dismutase (SOD), catalase (CAT), malondialdehyde (MDA), and glutathione (GSH) of albino rats receiving the same level of $\mathrm{CCl}_{4}$ as the positive control but treated with 2 levels of buffalo milk retentate hydrolysate $(\mathrm{RH}): 250 \mathrm{and} 500 \mathrm{mg} / \mathrm{kg}$ of $\mathrm{BW}$ per day [group (G) 3 and G4, respectively] compared with the negative and positive controls (G1 and G2, respectively). Different letters indicate significant differences $(P<0.05)$. Error bars represent standard deviations. 
The protective effect of RH at 2 dosages was substantiated by its capability to ameliorate adverse effects of $\mathrm{CCl}_{4}$ on serum total protein, albumin, and globulin by keeping them within the normal physiological range. The ability of RH to maintain normal levels of serum total lipids and triglycerides in albino rats after $\mathrm{CCl}_{4}$ exposure may indicate the potential of $\mathrm{RH}$ to mediate oxidative processes to maintain blood hemostasis.

The effect of $\mathrm{RH}$ on serum urea and creatinine levels, particularly at the high dosage, implies that the protective effect of $\mathrm{RH}$ is not limited to liver but is also potentially effective in restoring or maintaining renal physiology. These results showed that the protective effect of $\mathrm{RH}$ is generally against oxidative stress and may protect different organ tissues.

Superoxide dismutase, CAT, and glutathione peroxidase are cooperative defense systems that protect the body from free radical damage (Jalali Ghassam et al., 2014). The observed effect of $\mathrm{RH}$ on counteracting the drastic reduction in the levels of the antioxidant liver enzymes (SOD and CAT) induced by $\mathrm{CCl}_{4}$ exposure can be attributed to the general protective action of this agent in maintaining the anabolic process, including enzyme biosynthesis. In our study, $\mathrm{RH}$ effectively maintained physiological levels of different biomarkers except for SOD and CAT, which were lower than the levels in the negative control group. Thus, RH may exert its antioxidant action directly and more rapidly than by upregulating the expression of antioxidant enzymes. In addition, the low levels of CAT and SOD may refer to their contribution to oxidative stress (Nasri et al., 2014). Milk protein hydrolysates were shown to reduce the incidence of diabetes mellitus in rats, perhaps due to their potential antioxidant activities (Awad et al., 2016). Furthermore, yak casein hydrolysates prepared with alcalase showed a significant effect in attenuating free radicals of 2,2-diphenyl-1-picrylhydrazyl (DPPH), superoxide, and hydrogen peroxide (Mao et al., 2011). Whey protein hydrolysates exhibit strong antioxidant activity due to their high content of the low-molecularweight peptides (Peng et al., 2009).

The increased liver levels of MDA in the positive control group of albino rats indicated accumulation of lipid peroxidation products in liver tissue under the action of $\mathrm{CCl}_{4}$. Malondialdehyde is a principal product of lipid peroxidation and serves as an indicator of oxidative damage and cell injury (Lee et al., 2004). Oral administration of $\mathrm{RH}$ repressed the increase in MDA of rats injected with $\mathrm{CCl}_{4}$ by inhibiting the lipid oxidation pathway, probably by the potential antioxidant activity

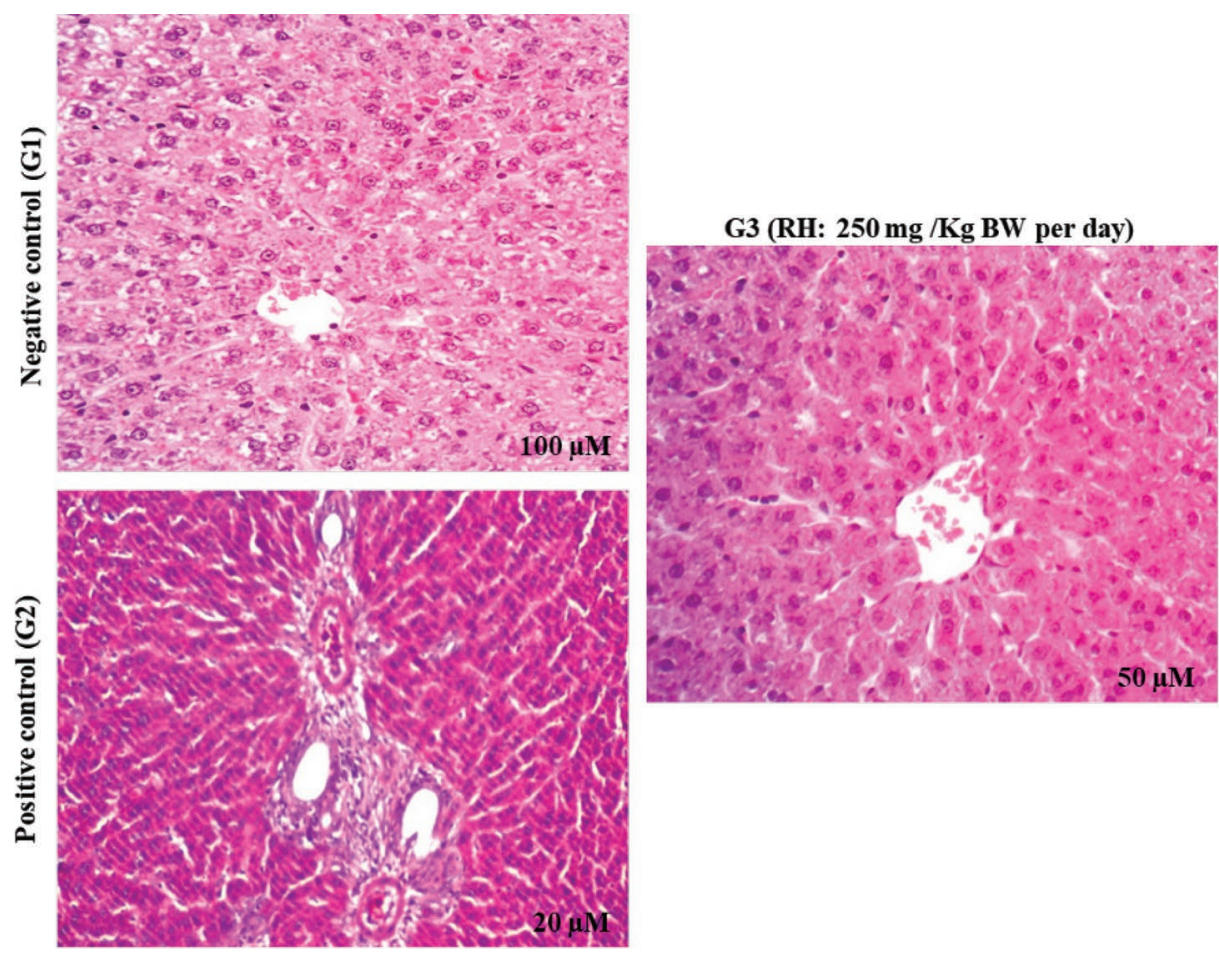

G4 (RH: $500 \mathrm{mg} / \mathrm{Kg} \mathrm{BW}$ per day)

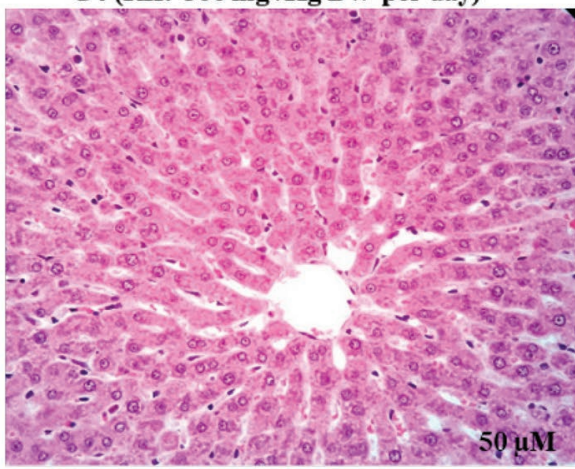

Figure 6. Liver histopathological profiles of albino rats intoxicated with $\mathrm{CCl}_{4}$ and simultaneously treated with 2 levels of buffalo skim milk retentate hydrolysate $(\mathrm{RH}): 250$ and $500 \mathrm{mg} / \mathrm{kg}$ of BW per day (G3 and G4, respectively) compared with the negative and positive controls (G1 and G2, respectively). Magnification power: $200 \times$. 
of $\mathrm{RH}$. The action of $\mathrm{RH}$ likely prevented lipid peroxidation through its high free radical scavenging activity (Abdel-Hamid et al., 2017), the main antioxidation mechanism for inhibiting the lipid peroxidation chain reaction (Vuda et al., 2012). The enhanced solvent accessibility to amino acid residues liberated by enzymatic hydrolysis may have improved their scavenging activity, as reported by Elias et al. (2008) and Osman et al. (2014), which consequently may preclude lipid oxidation.

Glutathione is a nonenzymatic biomarker critically responsive to tissue oxidative damage, and it shows several antioxidant activities that help maintain a balanced redox status (Athmouni et al., 2018). The ability of $\mathrm{RH}$ to alleviate the adverse effect of $\mathrm{CCl}_{4}$ on $\mathrm{GSH}$ levels and maintain normal values demonstrated the high in vivo antioxidant capacity of $\mathrm{RH}$ (due to its rich source of antioxidant peptides). Therefore, higher levels of GSH in the RH treatments may be attributed to a general effect on oxidative or antioxidative processes in living cells. Glutathione-s-transferase and GSH work together in scavenging free radicals and detoxifying the enzyme glutathione peroxidase (Messaoudi et al., 2010; Bargougui et al., 2019).

The liver histopathological status of albino rats treated with $\mathrm{RH}$ immediately after exposure to $\mathrm{CCl}_{4}$ confirmed the hepatoprotective ability of $\mathrm{RH}$, as indicated by the absence of major structural alterations incurred by $\mathrm{CCl}_{4}$ compared with the positive control $(\mathrm{G} 2)$ and the similarity of liver sections in the $2 \mathrm{RH}$ group to that of the negative control (G1). The RH contains bioactive peptides with free radical scavenging action that might preserve the histopathological status of $\mathrm{CCl}_{4}$-stressed albino rats (G3 and G4) close to normal status. These bioactive peptides may protect and maintain the integrity of cell membranes and decrease the permeability of the membrane to free radicals $\left(\mathrm{CCl}_{3}{ }^{\bullet}\right.$ and $\left.\mathrm{CCl}_{3} \mathrm{OO}{ }^{\bullet}\right)$.

The mechanism underlying the hepatoprotective action of RH may be correlated with the antioxidant effects of the released active peptides or through an indirect inhibitory action of ACE (Abdel-Hamid et al., 2017), preventing free radicals from attacking and disrupting cellular membranes and keeping their integrity. The ACE-inhibitory action and antioxidant activity are well correlated because angiotensin II stimulates nonphagocytic NADPH oxidase, causing the accumulation of hydrogen peroxide, superoxide, and peroxynitrite (Touyz et al., 2002). However, mixing ACE inhibitor with an antioxidant agent showed the same action (Fiordaliso et al., 2006), suggesting a common mechanism of action through reduction of oxidative stress. A further consideration in this respect is that $\mathrm{RH}$ may also upregulate mRNA expression of cellular antioxida- tive enzymes (SOD, GSH, and CAT), which also promote intracellular antioxidant mechanisms (Himaya et al., 2012).

\section{CONCLUSIONS}

Our results demonstrated potential health benefits of buffalo milk protein hydrolysates, as shown by the hepatoprotective effect on acute liver injury induced by $\mathrm{CCl}_{4}$ in male albino rats. Oral administration of $\mathrm{RH}$ at a low dosage $(250 \mathrm{mg} / \mathrm{kg}$ of BW per day) significantly limited the damage caused by oxidative stress induced by $\mathrm{CCl}_{4}$ exposure; however, the higher dosage of $\mathrm{RH}(500 \mathrm{mg} / \mathrm{kg}$ of BW per day) alleviated the damage almost completely (similar to the negative control group). This protective effect was probably achieved through direct antioxidant action against generated free radicals $\left(\mathrm{CCl}_{3}{ }^{\bullet} \text { and } \mathrm{CCl}_{3} \mathrm{OO}\right)^{\bullet}$. The mechanism of the hepatoprotective effect of RH may be the direct antioxidant action of the released active peptide sequences, an indirect inhibitory action on ACE, or upregulation of expression of antioxidant enzymes (SOD and CAT). These 3 potential pathways all enhance intracellular antioxidant mechanisms, preventing free radicals from affecting and disrupting the integrity of cell membranes.

\section{ACKNOWLEDGMENTS}

This study was supported by the Guangxi Key Research and Development Program, Guangxi, China (project no. AB1850017). The authors declare no conflicts of interest with respect to the research, authorship, and publication of this article.

\section{REFERENCES}

Abdel-Hamid, M., H. A. Goda, C. De Gobba, H. Jenssen, and A. Osman. 2016. Antibacterial activity of papain hydrolysed camel whey and its fractions. Int. Dairy J. 61:91-98. https://doi.org/10.1016/ j.idairyj.2016.04.004.

Abdel-Hamid, M., J. Otte, C. De Gobba, A. Osman, and E. Hamad. 2017. Angiotensin I-converting enzyme inhibitory activity and antioxidant capacity of bioactive peptides derived from enzymatic hydrolysis of buffalo milk proteins. Int. Dairy J. 66:91-98. https:/ /doi.org/10.1016/j.idairyj.2016.11.006.

Adler-Nissen, J. 1979. Determination of the degree of hydrolysis of food protein hydrolysates by trinitrobenzenesulfonic acid. J. Agric Food Chem. 27:1256-1262. https://doi.org/10.1021/jf60226a042.

Allain, C. C., L. S. Poon, C. S. Chan, W. Richmond, and P. C. Fu. 1974. Enzymatic determination of total serum cholesterol. Clin. Chem. 20:470-475.

Athmouni, K., D. Belhaj, K. Mkadmini Hammi, A. El Feki, and H. Ayadi. 2018. Phenolic compounds analysis, antioxidant, and hepatoprotective effects of Periploca angustifolia extract on cadmium-induced oxidative damage in HepG2 cell line and rats. Arch. Physiol. Biochem. 124:261-274. https://doi.org/10.1080/13813455 .2017.1395890.

Awad, S., M. El-Sayed, A. Wahba, A. El Attar, M. Yousef, and M. Zedan. 2016. Antioxidant activity of milk protein hydrolysate in 
alloxan-induced diabetic rats. J. Dairy Sci. 99:8499-8510. https:// doi.org/10.3168/jds.2015-10626.

Bargougui, K., K. Athmouni, and M. Chaieb. 2019. Optimization, characterization and hepatoprotective effect of polysaccharides isolated from Stipa parviflora Desf. against $\mathrm{CCl}_{4}$-induced liver injury in rats using surface response methodology (RSM). Int. J. Biol. Macromol. 132:524-533. https://doi.org/10.1016/j.ijbiomac .2019.03.216.

Bradford, M. M. 1976. A rapid and sensitive method for the quantitation of microgram quantities of protein utilizing the principle of protein-dye binding. Anal. Biochem. 72:248-254. https://doi.org/ 10.1016/0003-2697(76)90527-3.

Cai, X., A. Yan, N. Fu, and S. Wang. 2017. In vitro antioxidant activities of enzymatic hydrolysate from Schizochytrium Sp. and its hepatoprotective effects on acute alcohol-induced liver injury in vivo. Mar. Drugs 15:115. https://doi.org/10.3390/md15040115.

Díaz, M., C. M. Dunn, D. J. McClements, and E. A. Decker. 2003. Use of caseinophosphopeptides as natural antioxidants in oil-in-water emulsions. J. Agric. Food Chem. 51:2365-2370. https://doi.org/10 $.1021 /$ jf025984l.

Draper, H., and M. Hadley. 1990. Malondialdehyde determination as index of lipid peroxidation. Methods Enzymol. 186:421-431.

El-Hadary, A. E., and M. F. Ramadan Hassanien. 2016. Hepatoprotective effect of cold-pressed Syzygium aromaticum oil against carbon tetrachloride $\left(\mathrm{CCl}_{4}\right)$-induced hepatotoxicity in rats. Pharm. Biol. 54:1364-1372. https://doi.org/10.3109/13880209.2015.1078381.

El-Saadany, S., R. El-Massry, S. Labib, and M. Sitohy. 1991. The biochemical role and hypocholesterolaemic potential of the legume Cassia fistula in hypercholesterolaemic rats. Food/Nahrung 35:807-815.

Elias, R. J., S. S. Kellerby, and E. A. Decker. 2008. Antioxidant activity of proteins and peptides. Crit. Rev. Food Sci. Nutr. 48:430-441. https://doi.org/10.1080/10408390701425615.

Fiordaliso, F., I. Cuccovillo, R. Bianchi, A. Bai, M. Doni, M. Salio, N. De Angelis, P. Ghezzi, R. Latini, and S. Masson. 2006. Cardiovascular oxidative stress is reduced by an ACE inhibitor in a rat model of streptozotocin-induced diabetes. Life Sci. 79:121-129. https://doi.org/10.1016/j.lfs.2005.12.036.

Hamad, E. M., S. H. Taha, A.-G. I. Abou Dawood, M. Z. Sitohy, and M. Abdel-Hamid. 2011. Protective effect of whey proteins against nonalcoholic fatty liver in rats. Lipids Health Dis. 10:57. https:// doi.org/10.1186/1476-511X-10-57.

Himaya, S., D.-H. Ngo, B. Ryu, and S.-K. Kim. 2012. An active peptide purified from gastrointestinal enzyme hydrolysate of Pacific cod skin gelatin attenuates angiotensin-1 converting enzyme (ACE) activity and cellular oxidative stress. Food Chem. 132:1872-1882. https://doi.org/10.1016/j.foodchem.2011.12.020.

Jalali Ghassam, B., H. Ghaffari, H. Prakash, and K. R. Kini. 2014. Antioxidant and hepatoprotective effects of Solanum xanthocarpum leaf extracts against CCl4-induced liver injury in rats. Pharm. Biol. 52:1060-1068. https://doi.org/10.3109/13880209.2013.877490.

Jiang, L., J. Huang, Y. Wang, and H. Tang. 2012. Metabonomic analysis reveals the $\mathrm{CCl}_{4}$-induced systems alterations for multiple rat organs. J. Proteome Res. 11:3848-3859. https://doi.org/10.1021/ pr3003529.

Laborde, C., A. Chapa, D. Burleigh, D. Salgado, and J. Fernandez. 1995. Effects of processing and storage on the measurement of nitrogenous compounds in ovine blood. Small Rumin. Res. 17:159166. https://doi.org/10.1016/0921-4488(95)00665-8.

Lee, K. J., E.-R. Woo, C. Y. Choi, D. W. Shin, D. G. Lee, H. J. You, and H. G. Jeong. 2004. Protective effect of acteoside on carbon tetrachloride-induced hepatotoxicity. Life Sci. 74:1051-1064. https: //doi.org/10.1016/j.lfs.2003.07.020.

Mahmood, A., and S. Usman. 2010. A comparative study on the physicochemical parameters of milk samples collected from buffalo, cow, goat and sheep of Gujrat, Pakistan. Pak. J. Nutr. 9:1192-1197. https://doi.org/10.3923/pjn.2010.1192.1197.

Mahmoud, M. F., A. Fahmy, and M. A. Auf. 2012. Evaluation of the hepatoprotective effect of green tea extract and selenium on $\mathrm{CCl}_{4^{-}}$ induced fibrosis. e-SPEN J. 7:e23-e29.
Manibusan, M. K., M. Odin, and D. A. Eastmond. 2007. Postulated carbon tetrachloride mode of action: A review. J. Environ. Sci. Health. C Environ. Carcinog. Ecotoxicol. Rev. 25:185-209. https:/ /doi.org/10.1080/10590500701569398.

Mao, X.-Y., X. Cheng, X. Wang, and S.-J. Wu. 2011. Free-radicalscavenging and anti-inflammatory effect of yak milk casein before and after enzymatic hydrolysis. Food Chem. 126:484-490. https:// doi.org/10.1016/j.foodchem.2010.11.025.

Messaoudi, I., F. Hammouda, J. El Heni, T. Baati, K. Saïd, and A. Kerkeni. 2010. Reversal of cadmium-induced oxidative stress in rat erythrocytes by selenium, zinc or their combination. Exp. Toxicol. Pathol. 62:281-288. https://doi.org/10.1016/j.etp.2009.04.004.

Nasri, H., S. Behradmanesh, A. Ahmadi, and M. Rafieian-Kopaei 2014. Impact of oral vitamin D (cholecalciferol) replacement therapy on blood pressure in type 2 diabetes patients; a randomized, double-blind, placebo controlled clinical trial. J. Nephropathol. 3:29-33.

Osman, A., S. Abd-Elaziz, A. Salama, A. A. Eita, and M. Sitohy 2019. Health protective actions of phycocyanin obtained from an Egyptian isolate of Spirulina platensis on albino rats. EurAsian J. BioSci. 13:105-112.

Osman, A., G. M. El-Araby, and H. Taha. 2016a. Potential use as a bio-preservative from lupin protein hydrolysate generated by alcalase in food system. J. Appl. Biol. Biotechnol. 4:076-081.

Osman, A., H. A. Goda, M. Abdel-Hamid, S. M. Badran, and J. Otte. 2016b. Antibacterial peptides generated by alcalase hydrolysis of goat whey. Lebensm. Wiss. Technol. 65:480-486. https://doi.org/ 10.1016/j.lwt.2015.08.043

Osman, A., S. Mahgoub, and M. Sitohy. 2014. Hindering milk quality storage deterioration by mild thermization combined with methylated chickpea protein. Int. Food Res. J. 21:693-701.

Otte, J., M. Abdel-Hamid, and A. Osman. 2015. Comparative assessment of peptide concentration in milk protein hydrolysates and fractions. Int. J. Dairy Sci. 10:228-235. https://doi.org/10.3923/ ijds.2015.228.235.

Ou, Y., S. Zheng, L. Lin, Q. Jiang, and X. Yang. 2010. Protective effect of C-phycocyanin against carbon tetrachloride-induced hepatocyte damage in vitro and in vivo. Chem. Biol. Interact. 185:94100. https://doi.org/10.1016/j.cbi.2010.03.013.

Peng, X., Y. L. Xiong, and B. Kong. 2009. Antioxidant activity of peptide fractions from whey protein hydrolysates as measured by electron spin resonance. Food Chem. 113:196-201. https://doi.org/10 .1016/j.foodchem.2008.07.068.

Ramadan, M. F., M. M. A. Amer, and A. E.-S. Awad. 2008. Coriander (Coriandrum sativum L.) seed oil improves plasma lipid profile in rats fed a diet containing cholesterol. Eur. Food Res. Technol. 227:1173-1182. https://doi.org/10.1007/s00217-008-0833-y.

Reeves, P. G. 1997. Components of the AIN-93 diets as improvements in the AIN-76A diet. J. Nutr. 127:838S-841S.

Reitman, S., and S. Frankel. 1957. A colorimetric method for the determination of serum glutamic oxalacetic and glutamic pyruvic transaminases. Am. J. Clin. Pathol. 28:56-63. https://doi.org/10 $.1093 /$ ajcp/28.1.56.

Shenoy, K. A., S. Somayaji, and K. Bairy. 2002. Evaluation of hepatoprotective activity of Ginkgo biloba in rats. Indian J. Physiol. Pharmacol. 46:167-174.

Sitohy, M., A. Osman, A. Gharib, J.-M. Chobert, and T. Haertlé. 2013. Preliminary assessment of potential toxicity of methylated soybean protein and methylated $\beta$-lactoglobulin in male Wistar rats. Food Chem. Toxicol. 59:618-625. https://doi.org/10.1016/j .fct.2013.06.026.

Tabacco, A., F. Meiattini, E. Moda, and P. Tarli. 1979. Simplified enzymic/colorimetric serum urea nitrogen determination. Clin. Chem. 25:336-337.

Taha, H., and A. Osman. 2015. Assessment of antioxidant capacity of ethanolic extract of Portulaca oleracea leaves in vitro and in vivo. J. Med. Plants Res. 9:335-342. https://doi.org/10.5897/ JMPR2014.5757.

Touyz, R. M., X. Chen, F. Tabet, G. Yao, G. He, M. T. Quinn, P. J. Pagano, and E. L. Schiffrin. 2002. Expression of a functionally 
active gp91phox-containing neutrophil-type $\mathrm{NAD}(\mathrm{P}) \mathrm{H}$ oxidase in smooth muscle cells from human resistance arteries. Circ. Res. 90:1205-1213. https://doi.org/10.1161/01.RES.0000020404.01971 $.2 \mathrm{~F}$.

Vuda, M., R. D'Souza, S. Upadhya, V. Kumar, N. Rao, V. Kumar, C. Boillat, and P. Mungli. 2012. Hepatoprotective and antioxidant activity of aqueous extract of Hybanthus enneaspermus against CCl4-induced liver injury in rats. Exp. Toxicol. Pathol. 64:855859. https://doi.org/10.1016/j.etp.2011.03.006.

Wolf, P. L. 1999. Biochemical diagnosis of liver disease. Indian J. Clin. Biochem. 14:59-90. https://doi.org/10.1007/BF02869152.

Yang, X., S. Yang, Y. Guo, Y. Jiao, and Y. Zhao. 2013. Compositional characterisation of soluble apple polysaccharides, and their antioxidant and hepatoprotective effects on acute $\mathrm{CCl}_{4}$-caused liver damage in mice. Food Chem. 138:1256-1264. https://doi.org/10 .1016/j.foodchem.2012.10.030.
Yu, G.-C., J. Lv, H. He, W. Huang, and Y. Han. 2012. Hepatoprotective effects of corn peptides against carbon tetrachloride-induced liver injury in mice. J. Food Biochem. 36:458-464. https://doi.org/ 10.1111/j.1745-4514.2011.00551.x.

\section{ORCIDS}

M. Abdel-Hamid ๑ https://orcid.org/0000-0003-2833-2720

A. El-Hadary (i) https://orcid.org/0000-0002-5784-8606

E. Romeih ๑ https://orcid.org/0000-0003-2254-2866

L. Li i https://orcid.org/0000-0003-2948-6561 